\title{
Acute Behavioral Effects of Regrouping Dairy Cows
}

\author{
M. A. G. von Keyserlingk, ${ }^{1}$ D. Olenick, and D. M. Weary \\ Animal Welfare Program, University of British Columbia, 2357 Main Mall, Vancouver, British Columbia V6T 1Z4, Canada
}

\begin{abstract}
Regrouping is a common management practice on commercial dairy farms. The objectives of this study were to examine the effects of regrouping on feeding behavior, social behavior, and milk production. Eleven mid-lactation Holstein cows were individually introduced into previously established social groups. Behavior and milk production were monitored from $3 \mathrm{~d}$ before until $3 \mathrm{~d}$ after regrouping. Cows were fed a total mixed ration ad libitum twice daily. Time-lapse video was used to quantify feeding and social behavior. Cows spent approximately $15 \mathrm{~min}$ less time eating in the first hour following regrouping compared with the $3 \mathrm{~d}$ before regrouping. Cows were displaced from the feeding area on average 10 times/d before regrouping, but this value increased to more than 25 times $( \pm 2.6)$ on the day of mixing and gradually declined on the days following. The number of lying bouts declined from $12.2 \pm 0.9$ to $10.5 \pm 0.9$ on the day of regrouping; lying time showed a similar tendency. Cows initiated, on average, 7.5 \pm 1.3 allogrooming events/d over the $3 \mathrm{~d}$ before regrouping but this declined to $1.3 \pm 1.3$ events on the day of mixing and remained lower than baseline for the following 3 d. Milk production declined from $43.4 \pm 1.5 \mathrm{~kg} / \mathrm{d}$ to 39.7 $\pm 1.5 \mathrm{~kg} / \mathrm{d}$ on the day of regrouping, but did not differ from premixing levels on subsequent days. This study shows that regrouping can disrupt behavior and production in the hours and days following regrouping and suggests the need for future research to identify management changes that reduce these effects.
\end{abstract}

Key words: dairy cow, regrouping, feeding behavior, social behavior

\section{INTRODUCTION}

Changes in social environments can have pronounced effects on the physiology and behavior of animals (Zelena et al., 1999). Regrouping (also referred to as mixing or commingling) occurs frequently on dairy farms using

Received July 19, 2007.

Accepted November 21, 2007.

${ }^{1}$ Corresponding author: nina@interchange.ubc.ca loose housing, with most dairy cows being regrouped 4 to 5 times in a single lactation. Reasons for regrouping include the maintenance of homogeneous groups in terms of milk yield or stage of lactation (Grant and Albright, 2001).

Previous work has shown that when cows are regrouped they reestablish social relationships through threats, butting, and other nonphysical and physical interactions (Lamb, 1975; Kondo and Hurnik, 1990; Bøe and Færevik, 2003). Earlier work has shown that aggressive interactions increased dramatically in the hour after feed delivery on the day of regrouping but these effects stabilized on subsequent days (Brakel and Leis, 1976). Other work on regrouping suggested that social behavior returns to baseline levels between 5 and $15 \mathrm{~d}$ after regrouping (e.g., Kondo et al., 1984; Hasegawa et al., 1997).

Social competition is especially common at the feed bunk and can affect feeding times and intakes (e.g., Miller and Woodgush, 1991; DeVries et al., 2003; Huzzey et al., 2006). Hasegawa et al. (1997) exchanged primiparous cows between 2 groups and found that regrouped animals were frequently displaced from the feed bunk. Several researchers have noted a short-term decrease in milk yield of cows that were mixed into a new social group, possibly as a result of increased competitive interactions at the feed bunk, but others have found no change in milk yield (reviewed in Grant and Albright, 2001). One study showed that regrouping also disrupted the feeding behavior of grazing cows (Phillips and Rind, 2001), even though opportunities for competitive displacements are likely reduced on pasture.

Unfortunately, most of the previous research on this topic was either poorly replicated (e.g., Hasegawa et al., 1997; Phillips and Rind, 2001) or based on limited sampling methods (Brakel and Leis, 1976). Only one previous study has provided detailed measures of feeding and lying behaviors (Hasegawa et al., 1997). The primary aim of the current study was to test the shortterm effects of regrouping on the feeding, lying, and social behaviors of intensively managed mid-lactation cows. A secondary objective was to determine the impact of regrouping on milk production. 


\section{MATERIALS AND METHODS}

\section{Animals, Housing, and Diet}

A total of 80 high-producing, lactating dairy cows were used in this experiment. Cows were housed in a free-stall barn at The University of British Columbia Dairy Education and Research Centre (Agassiz, British Columbia, Canada) and divided into 4 groups of 11 and 3 groups of 12 cows/pen. Each pen had a total of 60 $\mathrm{cm}$ of accessible feed alley space/cow, and animals had access to the feed alley via a pendulous feed rail (see Huzzey et al. 2006). In each pen, 12 stalls filled with $40 \mathrm{~cm}$ of washed river sand were configured in 3 rows. The cows were fed a TMR consisting of $20 \%$ corn silage, $10 \%$ grass silage, $9 \%$ alfalfa hay, $11 \%$ third-cut grass hay, $15 \%$ steam-rolled corn, and $35 \%$ concentrate mash on a DM basis. The TMR was formulated according to the NRC (2001) recommendations for high-producing dairy cows. Fresh feed was provided at approximately 0600 and $1600 \mathrm{~h}$, and feed was pushed up closer to the cows at 1100 and $2200 \mathrm{~h}$ daily. Cows were milked between 0500 and $0530 \mathrm{~h}$ in the morning and between 1700 and $1730 \mathrm{~h}$ in the afternoon. Milk yields were automatically recorded at each milking. Artificial lighting in the barn turned on at $0445 \mathrm{~h}$ and off at $2100 \mathrm{~h}$ daily. Cows were managed according to the guidelines set by the Canadian Council on Animal Care (1993).

\section{Experimental Design}

Group Formation. Four cows from each of the 3 pens of 12 were randomly selected as focal animals. These cows had an average ( $\pm \mathrm{SD})$ parity of $2.33( \pm 1.23$; range 1-4), DIM of 148.50 ( \pm 13.82 ; range $125-171)$, BW of $685 \mathrm{~kg}( \pm 56.65 \mathrm{~kg}$; range $620-800)$, and projected 305 -d milk production of $12,187 \mathrm{~kg}( \pm 1,417 \mathrm{~kg}$; range 10,250-15,050). An additional 44 cows were housed in 4 pens of 11 cows each balanced for parity $(2.84 \pm 1.54$; mean \pm SD), DIM (133.75 \pm 27.80$)$, and projected 305$\mathrm{d}$ milk production $(12,233 \pm 2,441)$. All groups were kept stable for at least $7 \mathrm{~d}$ before any experimental regrouping.

Regrouping. Each focal cow was monitored in her home pen of 12 cows for $3 \mathrm{~d}$ before regrouping. Immediately after these baseline observations the cow was removed from her home pen and placed into 1 of the 4 test pens each containing a stable group of 11 cows, thus maintaining stocking for the focal cow at a constant 12 cows/pen. Cows were moved immediately after the morning milking and remained in the test group for 4 d. After the focal cow was removed and returned to her home pen, the groups were allowed $7 \mathrm{~d}$ to restabilize before the next focal cow was introduced.

\section{Behavioral Recording}

All behaviors were monitored for $7 \mathrm{~d}$ (from $3 \mathrm{~d}$ before to $4 \mathrm{~d}$ after regrouping). Feeding and social behaviors were recorded using Panasonic WV BP330 cameras positioned approximately $8 \mathrm{~m}$ above the experimental pens. The cameras were attached to a Panasonic video multiplexer (WV-FS416) and time-lapse recorder (AG6540p; all Panasonic equipment manufactured in Mississauga, Ontario, Canada). Red lights (100 W) were hung directly above (approximately $8 \mathrm{~m}$ ) the pens to facilitate video recording at night. Individual animals were identified with unique alphanumeric symbols made with hair dye.

Feeding behavior was monitored $24 \mathrm{~h} / \mathrm{d}$ using 1-min scan sampling, and the focal cow was recorded as "feeding" when the neck collar was on the feed-alley side of the tombstone separating the cows from the feed alley. All instances in which the focal cow was involved in an aggressive displacement at the feed bunk were recorded. The focal cow was considered displaced (reactor) from the feed bunk when the head of another cow (actor) came into contact with the front half of the reactor's body (from the ribs cranially) resulting in the reactor withdrawing from the feed (DeVries et al., 2004). All instances where the focal cow displaced (as actor) another cow (as defined above) were also recorded.

We used modified data loggers (Gemini Inc., Chichester, UK; see Huzzey et al., 2005) to quantify the number of lying bouts and the total time spent lying/d. The data logger was placed into a fabric pouch and attached to a hind leg of each focal cow for the $7 \mathrm{~d}$ sampling period. From the continuous video recordings we also recorded all instances where the focal cow was involved in an aggressive displacement at the lying area. A displacement from the lying area was recorded when the focal cow (actor) physically contacted the cow occupying the stall (that was either standing or lying) and the reactor left the stall, allowing the actor to enter the stall with at least 1 hoof. All instances where the focal cow was displaced (reactor) from a lying stall were also recorded.

The continuous video recordings were scored for allogrooming events involving the focal cow. The focal cow was considered the recipient of allogrooming when another cow began licking any part of her body. The focal cow was considered the initiator of the allogrooming event when she began licking another cow.

\section{Data Analysis}

All analyses considered the focal cow as the observational unit. One of the focal cows was in estrus at the time of regrouping and was removed from the analysis. All potential dependent variables were screened for normality and the presence of outliers by visual assessment 


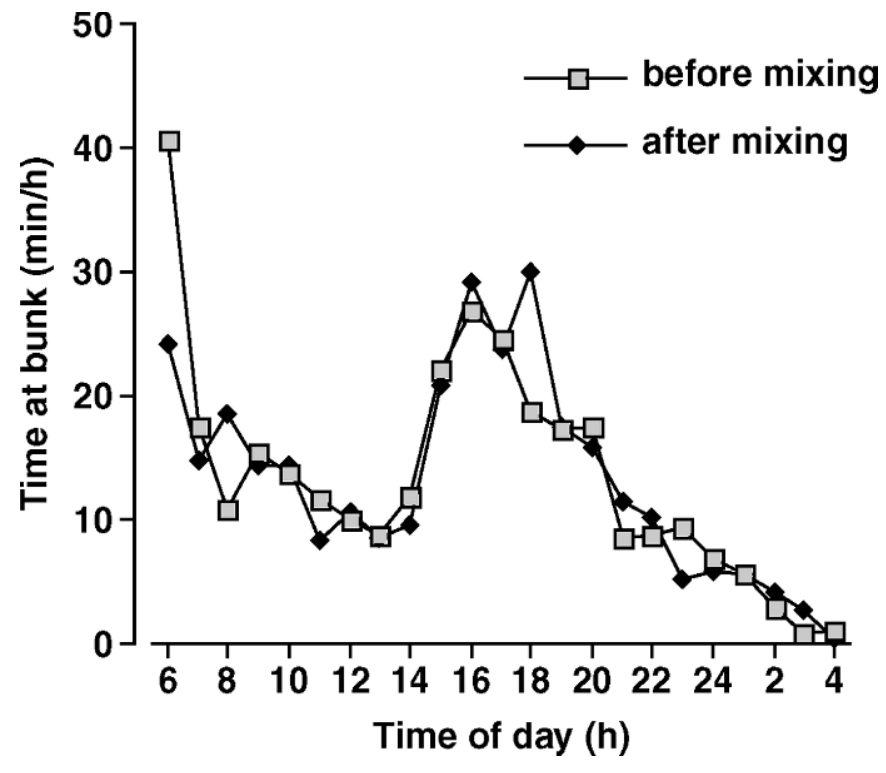

Figure 1. Time spent at the feedbunk $(\mathrm{min} / \mathrm{h})$ before and after regrouping. Cows were milked and fed at 0530 and $1730 \mathrm{~h}$. Data were averaged for the 11 focal cows and are shown starting at 0600 $\mathrm{h}$, the time when cows were regrouped. Fresh feed was provided at approximately 0600 and $1600 \mathrm{~h}$. Cows were regrouped after the morning milking on $\mathrm{d} 0$.

of the distributions (Proc Univariate in SAS, SAS Institute Inc., Cary, NC). We had no prediction of differences during the baseline period before mixing so responses were averaged for this period. We expected that the response to regrouping would be greatest on the day of regrouping, and responses would return to baseline on the days following. Responses on each of the days after regrouping were compared with the mean of the baseline observations using specified contrast statements within Proc Mixed. Contrasts (1 df) were tested against an error term with $39 \mathrm{df}$. Because each prediction was subjected to 4 tests (i.e., baseline vs. d 0, 1, 2, and 3 after regrouping), we adjusted our alpha level from 0.05 to 0.03 using the false discovery rate correction (Benjamini and Hochberg, 1995).

\section{RESULTS}

\section{Feeding Time}

Before regrouping the focal cows spent, on average, $300 \pm 9.3 \mathrm{~min} / \mathrm{d}$ feeding. Daily feeding time did not change on the day of regrouping, or on $d 1$ to 3 after regrouping, and the overall mean for the postmixing period was nearly identical at $299 \pm 11.2 \mathrm{~min} / \mathrm{d}$. However, when we accounted for diurnal variation in feeding behavior we found that feeding times in the hour after the delivery of fresh feed in the morning $(0600 \mathrm{~h})$ were lower after regrouping (Figure 1).

\section{Displacements from the Feeding Area}

Before regrouping, focal cows displaced others from the feeding area (i.e., as an actor) $11.7 \pm 5.7$ times/d and were displaced by others (i.e., as a reactor) $10.6 \pm$ 3.0 times/d. After mixing, the number of times focal cows were displaced increased, especially on the day of regrouping $(P<0.001)$, and remained higher than preregrouping on $\mathrm{d} 1(P=0.001)$ and $2(P=0.02)$ but not on d $3(P=0.14$; Figure 2$)$. There was no change in the number of times focal cows displaced others from the feeding area after regrouping.

\section{Lying Time}

Cows spent $13.1 \pm 0.5 \mathrm{~h} / \mathrm{d}$ lying down during the $3 \mathrm{~d}$ before regrouping. On the day that cows were mixed, lying time tended to decline (to an average of $12.4 \pm 0.5$ h; $P=0.06$ ) but there was no difference from baseline on the days following. The total lying time was divided into $12.2 \pm 0.9$ lying bouts/d before regrouping. This declined to $10.5 \pm 0.9$ bouts on the day of regrouping $(P<0.02)$ with no differences on any of the next $3 \mathrm{~d}$.

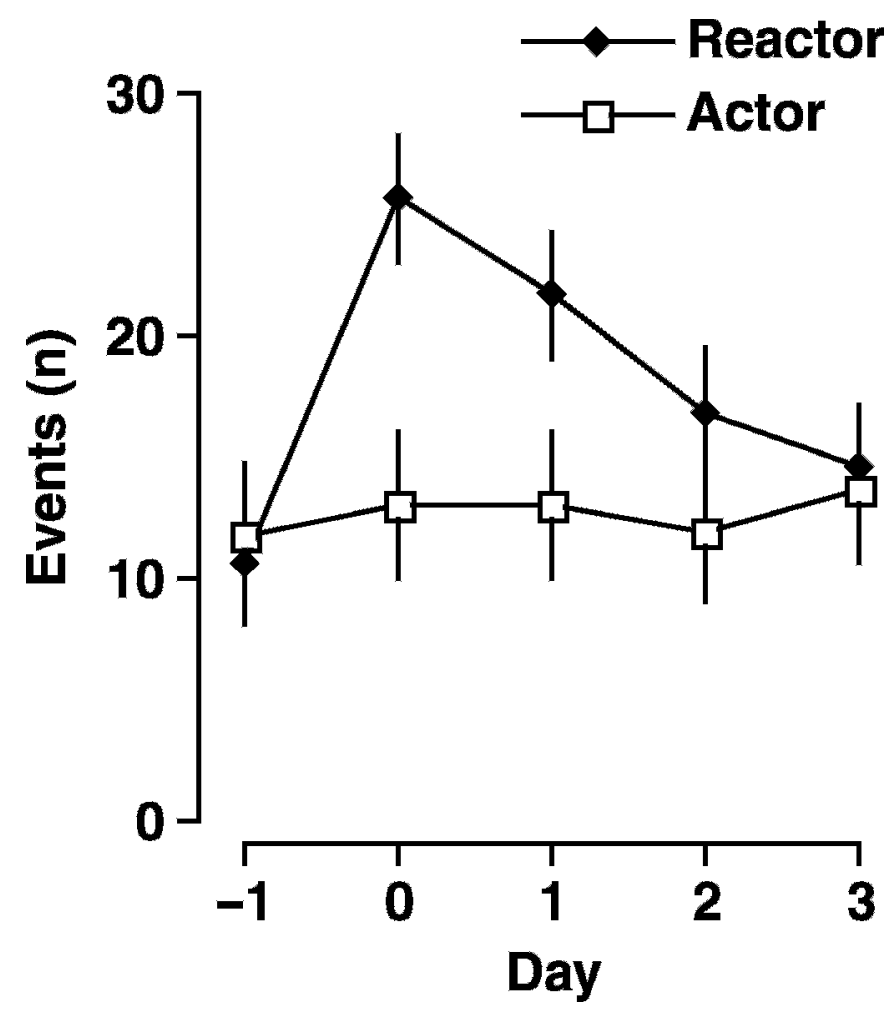

Figure 2. Number of competitive displacements, shown separately for the focal cow $(n=11)$ as actor and reactor and separately for $d$ -3 to $d-1$ (nominally $d-1$ ), d 0 (day of regrouping), and d 1,2 , and 3 after regrouping. Cows were regrouped after the morning milking on $\mathrm{d} 0$. 


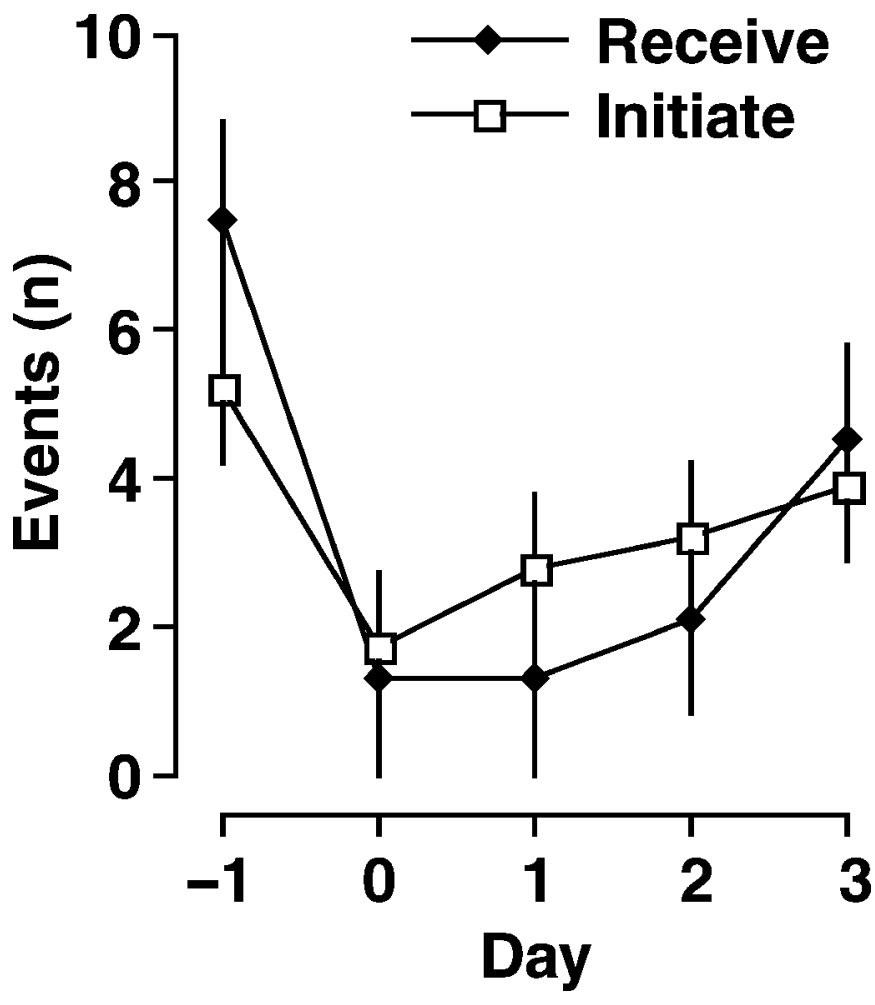

Figure 3. Number of allogrooming events, shown separately for focal cows $(\mathrm{n}=11)$ as receiver and initiator on the days before regrouping, $d-3$ to $d-1$ (nominally $d-1$ ), $d 0$ (day of regrouping), and $d 1$, 2 , and 3 following regrouping. Cows were regrouped after the morning milking on $\mathrm{d} 0$.

\section{Displacements from the Lying Area}

During the period before regrouping, focal cows displaced others from free-stalls (i.e., as actor) on average $2.0 \pm 0.4$ times/d, and were displaced by others (i.e., as reactor) $1.7 \pm 0.5$ times/d. After cows were mixed they were less likely to displace other cows on $\mathrm{d} 1 \mathrm{after}$ regrouping $(0.4 \pm 0.4$ displacements $/ \mathrm{d} ; P=0.002)$, but there was no difference from the pregrouping baseline on any other day. The number of times the focal cows were displaced by other cows did not differ after regrouping.

\section{Allogrooming}

Cows initiated on average $7.5 \pm 1.3$ allogrooming events/d over the $3 \mathrm{~d}$ before regrouping. On the day of regrouping the number of events initiated by the focal cows declined to $1.3 \pm 1.3$ (Figure $3 ; P=0.0003$ ), and remained lower than baseline on $d 1$ and 2 after regrouping $(P<0.002)$. Focal cows were the recipients of allogrooming events on average $5.2 \pm 1.0$ times/d before regrouping. This number declined to $1.7 \pm 1.0$ on the day of regrouping $(P=0.003)$, but was not different from baseline of subsequent days.

\section{Milk Production}

Milk production for the focal cows averaged $43.4 \pm$ $1.5 \mathrm{~kg} / \mathrm{d}$ before regrouping. After the cows were mixed, production dropped to $39.7 \pm 1.5 \mathrm{~kg}(P=0.0004)$ on $\mathrm{d} 1$ but was not different from baseline on subsequent days.

\section{DISCUSSION}

The time cows spent feeding was within the range reported previously for cows at this stage of lactation and housed in the same facility (DeVries and von Keyserlingk, 2006; Huzzey et al., 2006). Although we had predicted a reduction in feeding time on the days following mixing we only observed a minor change, significant only during the first hour after fresh feed delivery. DeVries et al. (2003) found that cows were most motivated to feed immediately after fresh feed delivery and that competition at the feed bunk is greatest at this time, so it is not surprising that the effects of mixing would be most apparent at this time. Previous work on pigs showed that feeding returned to baseline 4 to $5 \mathrm{~d}$ after mixing (Hyun et al., 1998), but the cows in the present study seemed able to reestablish premixing feeding patterns almost immediately. This difference may be because pigs generally show more overt aggression following mixing (Stookey and Gonyou, 1994), and may require a longer period to form stable relationships than cows.

Phillips and Rind (2001) also compared feeding behavior before and after mixing. They reported decreased grazing times for the mixed cows and attributed this decrease to increased aggressive interactions that interfered with foraging. In the current study cows showed a substantial increase in competitive displacements from the feeding area on the day of mixing and the 2 following days, but these displacements declined to near baseline levels $3 \mathrm{~d}$ after regrouping. O'Driscoll et al. (2006) studied small groups of calves fed from a computerized feeder, and found a reduced meal frequency only on the day of mixing and relatively few competitive displacements from the feeder before or after mixing.

Cows in this study decreased their lying times by nearly $1 \mathrm{~h}$ on the day of mixing but returned to premixing levels the following day. The decreased lying time on the day of mixing may have been due to focal cows being much less willing to displace others to gain access to a preferred lying stall. It is not clear why competitive displacement from the stall reduced after mixing, whereas displacements from the feeder in- 
creased. Cows each had access to one stall in the current study, but they also had access to the $0.60 \mathrm{~m}$ of feed bunk space/cow that is typically used by industry (Grant and Albright, 2001). Although, this amount of space is considered the lower limit by current industry standards (0.61 to $0.76 \mathrm{~m} / \mathrm{cow}$; Grant and Albright, 2001), it is the traditional amount of feed-bunk space typically used in commercial barns. The frequency of competitive interactions and displacements at the feed bunk were much higher than in the lying stalls, suggesting that that the design of the feeding area is more conducive to competition and displacements. Work in our group has shown that these competitive interactions at the feeding area can be reduced by providing more space per cow (DeVries et al., 2004; Huzzey et al., 2006), or by adding physical barriers between feeding positions much like those found between lying stalls (DeVries and von Keyserlingk, 2006). Although the cows in this study were not overstocked, previous work has shown that certain stalls are preferred and that cows will displace others from these stalls even when an open stall is available (Fregonesi et al., 2007). An increase in the number of aggressive interactions has also been reported in studies of overstocked dairy cows (Wierenga, 1983; Fregonesi and Leaver, 2002). Future work should focus on determining the impact of regrouping overstocked cows, because competition for lying spaces reduces lying times (Fregonesi et al., 2007), likely accentuating the effects of regrouping.

Social grooming is probably one of the most important affiliative social behaviors in cattle (Brownlee, 1950). Social grooming is a common cooperative behavior in nonhuman primates (Walters and Seyfarth, 1987), and is thought to reduce social tensions within the group (Aureli and de Waal, 1997). On this basis we expected an increase in allogrooming after mixing in the present study. Instead, we found a dramatic decline in allogrooming initiated by the focal cows. Previous work has found that allogrooming is most often initiated by socially subordinate individuals (e.g., cattle; Syme and Syme, 1979; Fraser and Broom, 1990). This behavior is not exclusively related to dominance relationships in cattle (Sato et al., 1993) and likely also facilitates the maintenance of social bonds.

Mixing of unfamiliar conspecifics can depress performance (Brakel and Leis, 1976) although this effect seems weak and variable across studies. Some studies have shown a slight reduction in milk yield immediately after mixing (e.g., Brakel and Leis, 1976; Hasegawa et al., 1997) but others have found no change in yields (e.g., Clark et al., 1977; Sowerby and Polan, 1978). Our results are consistent with this pattern, showing a significant reduction only on the first day after mixing.
One potential limitation of the current study, and indeed all studies on regrouping, is that it is impossible to maintain both a stable social structure and a stable stocking density among the nonfocal cows. In the current study we chose to maintain a stable group of 11 nonfocal cows, such that the stocking for the focal cow would remain at 12 cows per pen before and after regrouping, but this meant that stocking for the nonfocal cows increased from 11 to 12 at regrouping. One alternative approach would have been to maintain density for the nonfocal cows at 12 , but this would have required removing one cow from the group before introducing the focal cow, likely disrupting behavior within the group.

In the current study we introduced only one cow into an otherwise small, stable social group. A potential disadvantage of this design is that the social disruption is relatively minor compared with regrouping events that happen on-farm, where group size is often much larger. Future work is required to document changes in behavior and production associated with regrouping multiple cows and creating entirely new groups. Group size is also an important covariate to consider in future work. Stable social relationships, especially dominance relationships, can be difficult to maintain in very large groups, potentially reducing the disruptive effects of regrouping for large groups (Estevez et al., 2007).

\section{ACKNOWLEDGMENTS}

We thank the staff and students at The University of British Columbia's Dairy Education and Research Centre and the University's Animal Welfare Program. In particular, we thank Michelle Drissler for her help with the video analyses and David Val-Laillet and Trevor DeVries for their comments on the manuscript. Danica Olenick was supported in part by a Natural Sciences and Engineering Research Council of Canada Undergraduate Scholarship. The project was funded by the Natural Sciences and Engineering Research Council of Canada, through the Industrial Research Chair in Animal Welfare, and by contributions from the Dairy Farmers of Canada, the BC Dairy Foundation, the BC SPCA, members of the BC Veterinary Medical Association, and many other donors listed on our website at http://www.landfood.ubc.ca/animalwelfare.

\section{REFERENCES}

Aureli, F., and F. B. de Waal. 1997. Inhibition of social behavior in chimpanzees under high-density conditions. Am. J. Primatol. 41:213-228.

Benjamini, Y., and Y. Hochberg. 1995. Controlling the false discovery rate: A practical and powerful approach to multiple testing. J. R. Stat. Soc. B 57:289-300.

Bøe, K. E., and G. Færevik. 2003. Grouping and social preferences in calves, heifers and cows. Appl. Anim. Behav. Sci. 80:175-190. 
Brakel, W. J., and R. A. Leis. 1976. Impact of social disorganization on behavior, milk yield, and body weight of dairy cows. J. Dairy Sci. 59:716-721.

Brownlee, A. 1950. Studies in the behaviour of domestic cattle in Britain. Bull. Anim. Behav. 8:11-20.

Canadian Council on Animal Care. 1993. Guide to the Care and Use of Experimental Animals. Vol. 1. E. D. Olfert, B. M. Cross, and A. A. McWilliam, ed. CCAC, Ottawa, Canada.

Clark, P. W., R. E. Ricketts, and G. F. Krause. 1977. Effect on milk yield of moving cows from group to group. J. Dairy Sci. 60:769-772.

DeVries, T. J., and M. A. G. von Keyserlingk. 2006. Feed stalls affect the social and feeding behavior of lactating dairy cows. J. Dairy Sci. 89:3522-3531.

DeVries, T. J., M. A. G. von Keyserlingk, and K. A. Beauchemin. 2003. Diurnal feeding pattern of lactating dairy cows. J. Dairy Sci. 86:4079-4082.

DeVries, T. J., M. A. G. von Keyserlingk, and D. M. Weary. 2004. Effect of feeding space on the inter-cow distance, aggression, and feeding behavior of free-stall housed lactating dairy cows. J. Dairy Sci. 87:1432-1438.

Estevez, I., I. E. Andersen, and E. Nævdal. 2007. Too many, too few: Group size, density and social dynamics in farm animals. Appl. Anim. Behav. Sci. 103:185-204.

Fraser, A. F., and D. M. Broom. 1990. Farm Animal Behaviour and Welfare. 3rd ed. Baillière Tindall, London, UK.

Fregonesi, J. A., and J. D. Leaver. 2002. Influence of space allowance and milk yield level on behaviour, performance and health of dairy cows housed in straw yard and cubicle systems. Livest. Prod. Sci. 78:245-257.

Fregonesi, J. A., C. B. Tucker, and D. M. Weary. 2007. Overstocking reduces lying time in dairy cows. J. Dairy Sci. 90:3349-3354.

Grant, R. J., and J. L. Albright. 2001. Effect of animal grouping on feeding behavior and intake of dairy cattle. J. Dairy Sci. 84(E Suppl.):E156-E163.

Hasegawa, N., A. Nishiwaki, K. Sugawara, and I. Ito. 1997. The effects of social exchange between two groups of lactating primiparous heifers on milk production, dominance order, behavior and adrenocortical response. Appl. Anim. Behav. Sci. 51:15-27.

Huzzey, J. M., T. J. DeVries, P. Valois, and M. A. G. von Keyserlingk. 2006. Stocking density and feed barrier design affect the feeding and social behavior of dairy cattle. J. Dairy Sci. 89:126-133.

Huzzey, J. M., M. A. G. von Keyserlingk, and D. M. Weary. 2005. Changes in feeding, drinking, and standing behavior of dairy cows during the transition period. J. Dairy Sci. 88:2454-2461.
Hyun, Y., M. Ellis, and R. W. Johnson. 1998. Effects of feeder type, space allowance, and mixing on the growth performance and feed intake pattern of growing pigs. J. Anim. Sci. 76:2771-2778.

Kondo, S., and J. F. Hurnik. 1990. Stabilization of social hierarchy in dairy cows. Appl. Anim. Behav. Sci. 27:287-297.

Kondo, S., N. Kawakami, H. Kohama, and S. Nishino. 1984. Changes in activity, spatial pattern and social-behavior in calves after grouping. Appl. Anim. Ethol. 3:217-228.

Lamb, R. C. 1975. Relationship between cow behavior patterns and management systems to reduce stress. J. Dairy Sci. 59:16301636

Miller, K., and D. G. M. Woodgush. 1991. Some effects of housing on the social behavior of dairy cows. Anim. Prod. 53:271-278.

NRC. 2001. Nutrient Requirements for Dairy Cattle. 7th rev. ed. Natl. Acad. Sci., Washington, DC

O’Driscoll, K., M. A. G. von Keyserlingk, and D. M. Weary. 2006. Effects of mixing on drinking and competitive behavior of dairy calves. J. Dairy Sci. 89:229-233.

Phillips, C. J. C., and M. I. Rind. 2001. The effects on production and behavior of mixing uniparous and multiparous cows. J. Dairy Sci. 84:2424-2429.

Sato, S., K. Tarumizu, and K. Hatae. 1993. The influence of social factors on allogrooming in cows. Appl. Anim. Behav. Sci. 38:235-244.

Sowerby, M. E., and C. E. Polan. 1978. Milk production responses to shifting cows between intrabred groups. J. Dairy Sci. 61:155-160.

Stookey, J. M., and H. W. Gonyou. 1994. The effects of regrouping on behavioural and production parameters in finishing swine. J. Anim. Sci. 72:2804-2811.

Syme, G. J., and L. A. Syme. 1979. Social structure in farm animals. Elsevier, New York, NY.

Walters, J. R., and R. M. Seyfarth. 1987. Conflict and cooperation. Pages 306-317 in Primates Societies. B. B. Smuts, D. L. Cheney, R. M. Seyfarth, R. W. Wrangham, and T. T. Struhsaker, ed. The University of Chicago Press, Chicago, IL.

Wierenga, H. K. 1983. The influence of the space for walking and lying in a cubicle system on the behaviour of dairy cattle. Pages 171-180 in Farm Animal Housing and Welfare. S. H. Baxter, J. A. C. McLornack, and M. R. Baxter, ed. Martinus Nijhoff, The Hague, the Netherlands.

Zelena, D., J. Haller, and J. Halasz. 1999. Social stress of variable intensity: Physiological and behavioural consequences. Brain Res. Bull. 48:297-302. 